\title{
CLUBE DE OBSERVADORES DA NATUREZA: UM RETORNO À HISTORICIDADE DA CIÊNCIA POR PESQUISA DE INTERVENÇÃO EM AMBIENTE NATURAL
}

\author{
João Pedro Zanardo de Andrade ${ }^{1}$ \\ Camila Reis dos Santos ${ }^{2}$ \\ Leonardo Prest Merçon ${ }^{3}$ \\ Cristina Zampa Sanchêz ${ }^{4}$ \\ Viviana Borges Corte ${ }^{5}$
}

Resumo: As novas tendências da era globalizante e digital trouxeram repercussões para as novas gerações ao limitar a infância ao espaço de dentro de casa e, consequentemente, ao desconectar crianças do mundo natural. Nesse sentido, o presente estudo, por meio da metodologia de intervenção pedagógica em turmas dos anos finais do ensino fundamental, apresenta a "Observação da Natureza" como estratégia de educação científica. As discussões teóricas foram alicerçadas no alinhamento entre os momentos pedagógicos e a prática investigativa de Delizoicov (2009). Pelo estudo proposto, postula-se, na aprendizagem de Ciências, que o contato com a natureza é uma alternativa promissora para a abordagem de conceitos biológicos, ao mesmo tempo que reaproxima a realidade escolar da própria historicidade científica.

Palavras-chave: Observação da Natureza. Intervenção Pedagógica. Momentos pedagógicos. Prática investigativa. Historicidade científica.

1 Centro Universitário FAESA. Vitória, ES - E-mail: joaopedrozanardo@gmail.com

2 Universidade Federal do Espírito Santo. Vitória, ES - E-mail: camiletsreis@yahoo.com.br

3 Instituto Últimos Refúgios. Vitória, ES - E-mail: leonardomercon@gmail.com

4 Escola Serrana. Serra, ES - Email: cris.zampa38@gmail.com

5 Universidade Federal do Espírito Santo.Vitória, ES - E-mail: viviana.borges@gmail.com

Revbea, São Paulo, V. 16, № 4: 80-101, 2021. 
Abstract: The new trends of the globalizing and digital era have brought their due repercussions for the new generations by limiting childhood to the space inside the home and, consequently, by disconnecting children from the natural world. In this sense, the present study, through the methodology of pedagogical intervention in classes in the final years of elementary school, presents an "Observation of Nature" as a strategy for scientific education. The theoretical hypotheses were based on the alignment between the pedagogical moments and the investigative practice of Delizoicov (2009). By the proposed study, it is postulated, in Science learning, that contact with nature is a promising alternative for the approach of biological concepts, at the same time that it brings the school reality closer to its own scientific historicity.

Keywords: Observation of Nature, Pedagogical Intervention, Pedagogical Moments, Investigative practice, Scientific Historicity.

\section{Introdução}

Os diversos setores da atividade humana são influenciados pelas mudanças de uma nova era, cujos reflexos ressoam na economia, na política, na cultura e na educação. A substituição do trabalho artesanal pelo assalariado, marca uma ruptura com modelos "primitivos" de produção diante do apogeu das máquinas da revolução industrial, nos séculos XVIII e XIX (LOUREIRO; LIMA, 2009). Consequentemente, o avanço das tecnologias impõe uma nova realidade de transformações do modelo social e econômico, nas relações humanas e destas com o ambiente (LAYRARGUES, 2006).

Nesse contexto, a tecnologia e o meio ambiente tornam-se pilares de uma nova configuração de sociedade, exigindo a ressignificação das relações humanas. No entanto, o distanciamento entre ser humano e ambiente natural tem trazido problemas sociais, psicológicos e fisiológicos nas gerações que crescem em contextos isolados de sua própria natureza intrínseca e original (LOUV, 2009). Ademais, o ritmo acelerado de crescimento das cidades e o mercado de trabalho cada vez mais competitivo provoca rotinas apertadas com momentos raros de desfrute em áreas naturais, afastadas, em sua maioria, dos grandes centros urbanos.

Na esteira dessa compreensão, as novas tendências da era globalizante e digital trouxeram repercussões para as novas gerações ao limitar a infância ao espaço de dentro de casa e, consequentemente, ao desconectar crianças do mundo natural, conectando-as, cada vez mais, a um mundo virtual e aos instrumentos tecnológicos. De acordo com Louv (2009) essa tendência mundial tem implicações profundas no desenvolvimento saudável das crianças e para o futuro do planeta, pois cerceia os benefícios da interação com os ambientes naturais. Para Marinho (2014), ao reverso dessa tendência, o contato com a natureza transportado para o contexto educativo,-pois pode ser um instrumento facilitador da aprendizagem além de contribuir para a formação de um senso de responsabilidade ambiental coletivo 
Além da contextualização, as tendências atuais em Educação Ambiental recomendam propostas pedagógicas mais dinâmicas, de modo a propiciar aumento de conhecimentos, mudanças de valores e aperfeiçoamento de habilidades, para que o ser humano assuma atitudes e comportamentos sustentáveis (LAYRARGUES, 2006).

Dentro do contexto da educação em Ciências, o movimento Ciência, Tecnologia, Sociedade e Ambiente (CTSA) surge em questionamento aos avanços científicos e tecnológicos de um período "pós-grande indústria" e às repercussões sobre a presente sociedade mundializada. A abordagem CTSA contesta justamente o distanciamento entre o desenvolvimento científico e tecnológico e o bem-estar social (LIMA; COPELLO, 2007; LOUREIRO; LIMA, 2009).

Desse modo, a interlocução entre ensino de Ciências e uma Educação Ambiental crítica torna-se fundamental, pois permite aos cidadãos o devido engajamento para enfrentar os problemas e desafios socioambientais de forma consciente. Disso depende o investimento em se prover uma educação científica nas escolas a qual proporcionará ao sujeito cientificamente letrado um discernimento sobre conceitos e métodos científicos.

A educação científica, por sua vez, exige novos paradigmas metodológicos com a adoção de práticas de ensino investigativas e ativas. Como preconizado por Teixeira (2003, p. 178), "[...] a ciência que é ensinada nas escolas sustenta uma imagem idealizada e distante da realidade do trabalho dos cientistas". Essa constatação é traduzida pelo desinteresse e por uma visão superficial acerca do papel da ciência e dos benefícios sociais às comunidades humanas dela advindos, o que pode causar um distanciamento dos alunos e o "fazer ciência".

Instigar o prazer por aprender Ciências constitui-se, portanto, um desafio não somente sob a ótica metodológica (ora, é cediço que está cada vez mais difícil prender a atenção dos alunos em uma única atividade, por mais interessante que ela possa parecer), mas também pela perspectiva da formação de cidadãos cientificamente críticos e com consciência socioambiental.

Nesse ínterim, nosso objetivo principal foi o de investigar práticas de "Observação da Natureza" como estratégias de educação científica e de fomento a ações de desenvolvimento sustentável. Ainda, neste estudo, visamos: a) destacar a importância da preservação da natureza para o bem estar social; b) despertar o fazer artístico e criativo dos alunos após contato com ambientes naturais; c) fomentar o uso das tecnologias digitais e da internet para fins de pesquisa e investigação, de forma criativa e consciente; d) integrar as famílias dos sujeitos participantes às ações educativas de Educação Ambiental; e) desenvolver ações de educação científica pelo estímulo à investigação, à experimentação, à argumentação e à problematização, próprios da cultura da ciência. 
O estudo se debruça sobre as unidades temáticas e habilidades exigidas pela Base Nacional Comum Curricular (BNCC) (BRASIL, 2016), bem como está em consonância com os objetivos do desenvolvimento sustentável da Agenda 2030 da Organização das Nações Unidas (ONU)(NAÇÕES UNIDAS BRASIL, 2021).

\title{
A observação da natureza enquanto estratégia para a educação científica: um retorno à historicidade da ciência e conexão com o ambiente natural
}

\begin{abstract}
[...] Encontrei, entre outras, algumas plantas da família de ericáceas; várias umbelíferas de folhas simples. Grande número de eriocaulons; duas ou três espécies de vellozia; uma surpreendente variedade de melastomatáceas [...] Povoam-na, ainda, melastomatáceas de pequenas folhas, algumas mirtáceas aveludadas, rubiáceas com folhas de urzes, no meio dessas plantas, encontrei algumas que ainda não recolhera até então... (Descrição de Saint-Hilaire sobre sua visita ao Brasil entre 1816 e 1822. O francês naturalista montou um herbário de mais de 7 mil espécies, das quais 4,5 mil eram desconhecidas dos cientistas à época) (PADOAN, 2015, p. 198).
\end{abstract}

A ciência carrega os benefícios e a essencialidade que seus avanços propiciaram no desenvolvimento das comunidades humanas ao longo da história. Esse legado é irrefutável. Entretanto, é perceptível que a tradução da linguagem e da cultura científica para a esfera educativa parece desconsiderar as marchas e contramarchas dessa história. O currículo de Ciências expresso nas escolas costuma transmitir uma linearidade do pensamento em torno da ciência bem como a inexistência de conflitos que marcaram as grandes descobertas e pesquisas da humanidade. A essa visão distorcida acerca da ciência inclui-se a figura do cientista, tido como uma personalidade distinta ora emblemática, ora caricata - um ser com mente iluminada e isento de sua própria historicidade (SANTOS et al., 2020).

A problemática da descaracterização da ciência e dos cientistas é, inclusive, a-histórica, haja vista os primórdios das pesquisas em Ciências Naturais já desenvolvidas pelos viajantes naturalistas desde os séculos XVIII e $\mathrm{XIX}$. Relatos das grandes navegações narram o trabalho dos encarregados súditos da Coroa Portuguesa na descrição das riquezas e dos recursos naturais existentes no Brasil colônia (PADOAN, 2015). Logo, o exercício investigativo fazia parte do cotidiano desses viajantes que, embora sem uma denominação oficial de cientistas, trouxeram grande impacto para o campo da biologia, para o estudo da natureza e do ambiente. Com as grandes expedições europeias ao Brasil, a partir do século XIX, a paisagem e seus elementos, de maneira geral, tornaram-se o laboratório desses estudiosos (PADOAN, 2015).

revista brasileira educação ambiental 
A ilustração dos primeiros laboratórios naturais tem como atores principais importantes nomes europeus de diversas nacionalidades. $\mathrm{Na}$ primeira metade do século XIX, uma expedição organizada pelo príncipe alemão Maximilian de Wied von Neuwied conduziu a coleta de uma série de vertebrados terrestres do sudeste brasileiro que foram, posteriormente, catalogados e publicados em revistas científicas daquele tempo (VANZOLINI, 1996).

Na mesma época, o naturalista Johann Christian Mikan juntamente com os coletores Johann Natterer e Dominick Sochor coordenaram a comissão austríaca ao Brasil e, durante 18 anos em território nacional, catalogaram diferentes tipos de espécies da avifauna. Natterer era uma figura de destaque por sua habilidade notável em taxidermia, além de ter sido o pioneiro em adotar o método de anotação, em etiqueta individual para cada espécime, com descrição de localidade, data, medidas do exemplar, sexo e cor das partes moles (VANZOLINI, 1996).

Em relação às expedições francesas ao Brasil, Vanzolini (1996) relata em seu trabalho as experiências da equipe dirigida pelo naturalista e diplomata Conde de Castelnau. As narrativas documentais de Castelnau trazem detalhes sobre as localidades visitadas, além da descrição de dados ecológicos, espécies coletadas e pesquisas paleontológicas realizadas.

No estudo sobre paisagem, ambiente e ciência no Brasil, Padoan (2015) aponta que o século XIX foi sensivelmente importante para a história das ciências naturais pelo impacto sobre a sistemática faunística e florística. Além dos naturalistas europeus já citados, o autor faz menção ao médico Georg Heinrich von Langsdorff, em virtude dos esforços dispensados à pesquisa com fauna e flora em território brasileiro, bem como, movido pela curiosidade do trabalho investigativo, das inúmeras ilustrações zoológicas e botânicas de autoria do próprio naturalista.

Outras duas figuras relevantes para os primórdios da história natural foram Saint-Hilaire e Carl Friedrich Philipp von Martius. A passagem de SaintHilaire pelo Brasil foi marcada pela ampla descrição e identificação de plantas, com alcance de 7000 espécies catalogadas. Sua inclinação ao exercício da pesquisa era evidente nos relatórios de viagem de sua autoria, o que o fez ser nomeado por alguns historiadores como "homem-cientista". Saint-Hilaire incorporava ao seu trabalho investigativo o zelo com relação às observações da natureza, ao mesmo tempo que demonstrava criteriosidade nas análises e julgamentos dos fenômenos. Nesse sentido, seu rigor metódico, próprio da ciência, o constituía enquanto pesquisador e "cientista natural". Carl Friedrich Philipp von Martius, contemporâneo de Saint-Hilaire seguiu os mesmos métodos de observação, coleta e análise do então conhecido como homemcientista, descrevendo desde florestas a campos, o meio natural e o próprio componente humano (PADOAN, 2015).

As contribuições das observações dos naturalistas aqui referidos foram inestimáveis ao campo das ciências naturais e fundamentam de forma oportuna as discussões pretendidas para este tópico. Vivemos uma série de 
tendências contemporâneas que convergem para uma consciência intensificada entre o bem-estar humano, a capacidade de aprender e a saúde ambiental. $\mathrm{O}$ transtorno de déficit de natureza, embora não seja um diagnóstico oficial, descreve a alienação da natureza pelo ser humano, que por sua vez gera custos e prejuízos progressivos como o uso diminuído dos sentidos, dificuldades de atenção, aumento das taxas de doenças físicas e emocionais (CHARLES et al., 2008).

$\mathrm{Na}$ contramão dos déficits desencadeados pelo distanciamento do ambiente natural, a observação das interações e dos processos da natureza relaciona-se com a própria harmonia do intelecto e do orgânico, pois é intrínseco ao humano. A prática de nossos primeiros cientistas naturais, como Saint-Hilaire, mencionado nas linhas introdutórias deste tópico, já sinalizava essa perspectiva. O "homem-cientista" utilizava,

[...] de todo o aparato disponível pelos sentidos humanos para sua observação, a audição, o olfato, o paladar e principalmente o tato e visão. Dessa forma [...] não observou somente as interações e os processos cíclicos da natureza, ele observou a vida, com um olhar ligado a mente e outro ligado ao coração. Assim [...] qualquer relação mais íntima com qualquer planta acaba por gerar afeto, ternura, carinho e, sobretudo, respeito. Nesse sentido, legitimando que para conhecer uma planta, é preciso primeiro conhecer o solo, entender o sol, do ciclo da água, da fauna e saber acerca do tempo e espaço (PADOAN, 2015, p. 199).

Logo, a convergência se concentra aqui, em que a opção por aulas de campo e por estratégias didáticas que explorem o ambiente natural nos aproxima da própria origem do conhecimento científico historicamente produzido e de seu legado, além de propiciar a construção de uma identidade com relação aos patrimônios naturais próprios da cultura de cada indivíduo. Ora, agora nos parece possível imaginar uma foto típica de um pesquisador do século XIX: certamente esse cientista estava ao "ar livre".

\section{Percurso metodológico}

O estudo em questão é de base qualitativa, calcado em pesquisa de intervenção pedagógica (DAMIANI et al., 2013). A investigação foi organizada por momentos pedagógicos (DELIZOICOV; ANGOTTI, 1990; DELIZOICOV; ANGOTTI; PERNAMBUCO, 2002; 2009) conduzidos em aulas de campo, em visitas a espaços não formais de educação e em intervenção em ambiente escolar.

Partiu-se de um projeto denominado Clube de Observadores da Natureza, idealizado pelo Instituto Últimos Refúgios, em consonância com o objetivo 4 da Agenda 2030 que preconiza "garantir que todos os alunos 
adquiram conhecimentos e habilidades necessárias para promover o desenvolvimento sustentável, inclusive, entre outros, por meio da educação para o desenvolvimento sustentável e estilos de vida sustentáveis" (NAÇÕES UNIDAS BRASIL, 2015)

Esse clube foi formado com alunos de uma escola pública da Serra-ES mediante a aprovação do Comitê de Ética. Na amostra da pesquisa foi privilegiada uma turma mista de alunos matriculados entre o $7^{\circ}$ e $9^{\circ}$ ano do ensino fundamental, professores de Ciências, de Geografia e de Língua Portuguesa, pesquisadores do Instituto Últimos Refúgios e voluntários observadores de aves.

Dentre as atividades, foram realizadas visitas guiadas a diferentes áreas naturais da Região Metropolitana do Espírito Santo, conforme etapas estruturadas e descritas no Quadro 1.

Quadro 1: Etapas da pesquisa de intervenção pedagógica com descrição dos Momentos Pedagógicos (3MPs)

\begin{tabular}{|c|c|c|}
\hline $\begin{array}{l}\text { Momento } \\
\text { Pedagógico }\end{array}$ & $\begin{array}{l}\text { Etapas da } \\
\text { Pesquisa de } \\
\text { Intervenção }\end{array}$ & Ações \\
\hline $\begin{array}{l}\text { Estudo da } \\
\text { Realidade (ER) }\end{array}$ & Sensibilização & $\begin{array}{l}\text { Momento de socialização das concepções prévias dos } \\
\text { alunos. Apresentação do "Clube de Observadores da } \\
\text { Natureza". Local: Escola. }\end{array}$ \\
\hline \multirow[t]{3}{*}{$\begin{array}{l}\text { Organização do } \\
\text { Conhecimento } \\
\text { (OC) }\end{array}$} & $\begin{array}{l}\text { Oficina de } \\
\text { Observação }\end{array}$ & $\begin{array}{l}\text { Exploração do ambiente escolar. Local: Pátio da } \\
\text { escola. }\end{array}$ \\
\hline & Uso de TDICs ${ }^{1}$ & $\begin{array}{l}\text { Manipulação da plataforma "Biofaces" }{ }^{2 "} \text { e uso de } \\
\text { smartphones para catalogar espécies. Criação de } \\
\text { grupo de "WhatsApp" com alunos participantes. }\end{array}$ \\
\hline & $\begin{array}{l}\text { Aula de } \\
\text { Campo }\end{array}$ & $\begin{array}{l}\text { Visitas a espaços não formais de educação. } \\
\text { Locais: Horto da Serra; APA }{ }^{3} \text { Mestre Alvaro; Ilha do } \\
\text { Frade e Parque Botânico da Vale. }\end{array}$ \\
\hline \multirow{3}{*}{$\begin{array}{l}\text { Aplicação do } \\
\text { Conhecimento } \\
\text { (AC) }\end{array}$} & \multirow{3}{*}{$\begin{array}{l}\text { Mural digital de } \\
\text { fotos }\end{array}$} & Postagem das fotografias dos alunos na plataforma. \\
\hline & & $\begin{array}{l}\text { Divulgação científica do trabalho realizado com } \\
\text { notícias publicadas em site do Instituto Últimos } \\
\text { Refúgios. }\end{array}$ \\
\hline & & $\begin{array}{l}\text { "Biofaces" com descrição das espécies catalogadas e } \\
\text { local de incidência. }\end{array}$ \\
\hline
\end{tabular}

${ }^{1}$ Tecnologias Digitais de Informação e Comunicação.

${ }^{2}$ Rede social de compartilhamento de fotos e vídeos de animais, sua localização e o nome científico.

3 Área de Proteção Ambiental 


\section{Sensibilização}

Nesta etapa inicial de intervenção, buscou-se a sensibilização dos estudantes por meio de apresentação oral sobre a biodiversidade no estado do Espírito Santo (Figura 1). O objetivo foi instigar a curiosidade e o interesse dos alunos em conhecer a riqueza da fauna espírito-santense. Foram compartilhadas experiências reais do preletor-pesquisador sobre atividades de pesquisa e observação da natureza trazendo o assunto para dentro do contexto local dos alunos.

Após motivar e despertar a natureza investigativa dos estudantes, foi aberto o convite para participação em um Clube de Observadores da Natureza. Os alunos interessados receberam um Termo de Consentimento Livre e Esclarecido, sendo orientados sobre o teor do documento e a necessidade da anuência dos responsáveis.

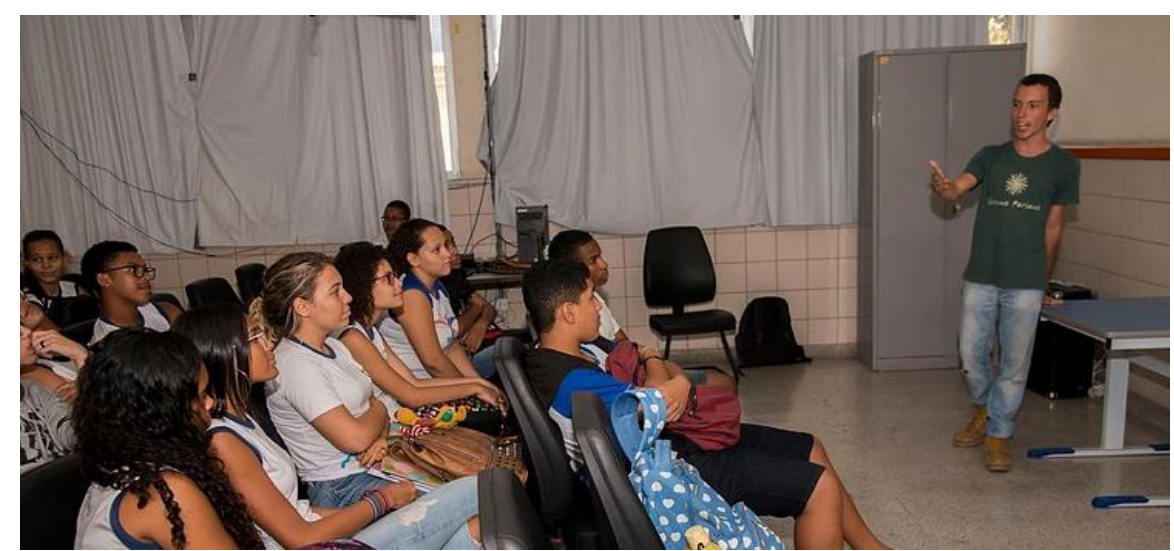

Figura 1: Etapa de "Sensibilização" com estudantes de escola pública no Município de Serra-ES.

\section{Oficina de Observação}

Após devidas orientações sobre as especificidades de uma atividade em campo, os alunos participaram de uma "Oficina de observação" no pátio da escola. A escolha pelo pátio como "local de investigação" se deu pela facilidade de acesso; por ser considerado uma menor escala de campo; pela identificação dos alunos enquanto espaço de pertencimento e pelo "despertar" para a presença da natureza em diversos espaços, inclusive os "urbanos" ao nosso redor.

Durante essa etapa, os alunos puderam ver e registrar aves, insetos e répteis que, embora comuns no ambiente urbano, podem passar despercebidos por hábitos humanos que negligenciam e invisibilizam a natureza. A oficina de observação "orientou" os estudantes no sentido de aguçar todos os sentidos na percepção do ambiente e sobre o que seria feito em campo, posteriormente. 


\section{Uso de TDICs}

Dentre as intencionalidades do projeto buscou-se a promoção da cidadania da ciência pela socialização do conhecimento em plataformas de pesquisa e compartilhamento de informações com uso da internet. Também foi criado um grupo no Whatsapp como fórum livre de interação dos alunos/familiares com biólogos, professores e observadores de aves voluntários do instituto. Por meio dessa funcionalidade, os registros fotográficos foram compartilhados e os alunos participantes, juntamente com seus responsáveis, puderam esclarecer dúvidas acerca da identificação e da caracterização das espécies, como etapa prévia à atividade de catalogação em plataforma de pesquisa.

A plataforma Biofaces foi escolhida para registro das espécies fotografadas pelos alunos. O site apresenta um template que permite a criação do perfil dos "pesquisadores", envio de fotos, vídeos, áudios, e inserção da localização, data e nome da espécie catalogada. As informações ficam disponíveis para que qualquer pessoa no mundo possa acessar, contribuem como fonte de consulta para pesquisas científicas (SOUSA, 2016) e, assim, se constitui como uma ferramenta potente no exercício da ciência cidadã. Mamede (2017) relata como o uso das plataformas de compartilhamento online de informações, incluindo o Biofaces, têm contribuído para a conservação da biodiversidade por meio da promoção da ciência cidadã. Nesta etapa os alunos fizeram uso de TDICs como ferramentas de pesquisa, o que possibilitou novas formas de socialização dos conhecimentos científicos e estimulou o espírito investigativo e a experimentação, próprios da cultura do pesquisador.

\section{Aula de Campo}

Nesta etapa deu-se início às visitas em áreas naturais, com escolha por quatro espaços não formais de educação, localizados no município de abrangência da escola: Serra, localizado na Microrregião de Vitória e na Mesorregião Central Espírito-Santense e reconhecido como o mais populoso município do estado do Espírito Santo, conforme estimativa, de 2019, do Instituto Brasileiro de Geografia e Estatística (IBGE).

Foram visitados: Jardim Botânico Horto da Serra, Área de Proteção Ambiental (APA) Mestre Álvaro, Parque Botânico Vale e llha do Frade. Os critérios para seleção dos espaços de visita incluíram a acessibilidade e a possibilidade de retorno dos alunos com seus familiares em momento posterior ao projeto. As peculiaridades de cada ambiente natural possibilitaram diferentes perspectivas acerca da riqueza da biodiversidade animal no estado do Espírito Santo.

Durante as visitas, os alunos puderam colocar em prática os conhecimentos adquiridos na "Oficina de Observação" e desenvolver habilidades criativas e artísticas no registro das observações.

O momento das "aulas de campo" possibilitou o contato com espécies nunca antes vistas pelos alunos, além da visita a espaços urbanos 
desconhecidos pela maioria dos participantes. Logo, o ineditismo nesses dois âmbitos conferiu maior relevância ao projeto, elevando os aprendizados a experiências marcantes na vida dos alunos.

\section{Mural Digital de Fotos}

A culminância do projeto ocorreu com a publicação das fotos e dos vídeos produzidos pelos alunos no perfil dedicado ao Clube na plataforma Biofaces, em forma de um "mural digital". Também foram divulgadas notícias no site do Instituto Últimos Refúgios para a promoção dos trabalhos dos alunos e como estratégia de incentivo ao compartilhamento dos resultados provenientes de um "trabalho de pesquisa investigativo".

No mural digital foram disponibilizadas informações acerca do nome científico e popular das espécies identificadas, a localização, a data e o nome do pesquisador (aluno que registrou a foto ou vídeo). Isso possibilitou um intercâmbio entre "observadores da natureza", pesquisadores e estudantes, na perspectiva de uma ciência cidadã em que as contribuições e os conhecimentos são compartilhados.

\section{Os momentos pedagógicos: experiências de observação, pesquisa e divulgação científica sobre ambientes naturais}

Neste tópico serão catalisadas discussões e impressões acerca da pesquisa de intervenção realizada, que teve como aporte teórico Delizoicov; Angotti (1990) e Delizoicov; Angotti; Pernambuco (2002; 2009) no tocante das formulações elaboradas em torno dos momentos pedagógicos.

Os três momentos pedagógicos (3MPs) podem ser entendidos como a transposição da concepção freireana sobre aprendizagem para o contexto da educação formal e são assim intitulados: estudo da realidade (ER); organização do conhecimento $(\mathrm{OC})$ e aplicação do conhecimento (AC).

\section{Estudo da realidade $(E R)^{2}$}

"Às vezes a gente não dá valor ao que está perto, olhamos as coisas dos outros países, cidades etc. Achamos mais belas e nem olhamos ao redor [...] Quem diria que aqui no ES teria coisas bonitas? Aqui na Serra então sem se fala!'3

\footnotetext{
${ }^{2}$ Considerado o primeiro momento pedagógico, recebeu nova denominação de "Problematização" a qual vem sendo postulada desde sua publicação, no final dos anos 1980, nas obras Física (1990) e Metodologia do Ensino de Ciências (1990).

${ }^{3}$ Trecho de poema elaborado por aluna do $7^{\circ}$ ano participante da pesquisa de intervenção.
}

revista brasileira 
A superação do dogmatismo parece ser uma das necessidades fundamentais do ensino de Ciências no contexto da Educação Básica. Entretanto, na prática, os conhecimentos científicos foram transmitidos e pensados historicamente como produtos finais, pela exposição direta e unilateral do professor. Nas palavras de Carvalho: "[...] transmitia-se os conceitos, as leis e as fórmulas. Os alunos replicavam as experiências $e$ decoravam os nomes dos cientistas" (CARVALHO, 2013, p. 1).

Nesse contexto, a problematização aparece como um processo de transformação, de construção de um novo olhar sobre aquilo que, aparentemente, já nos é familiar (e não como um acesso a algo que já vem pronto), propiciando o exercício da argumentação, a reflexão e participação ativa do estudante na busca pela compreensão/solução de conflitos (CAPECCHI, 2013).

A problematização exige um esforço contínuo de investigação, em que diversas interações ocorrem simultaneamente: interações entre pessoas, interações entre pessoas e conhecimentos prévios, interações entre pessoas e objetos. Portanto, todas são importantes, pois possibilitam a construção de um trabalho argumentativo, reflexivo e consciente no campo do ensino de Ciências (SASSERON, 2013).

Nesse sentido, uma concepção mais realista da ciência só faz sentido quando os conhecimentos são construídos dialogicamente: nem transmitidos, nem revelados, mas produzidos na ação/reflexão conjunta interativa. Essa construção socializada exige a consideração daquilo que os alunos trazem consigo, de seus contextos socioculturais e experiências - os chamados saberes prévios.

Freire (2003) colabora para essa reflexão quando advoga em prol da superação de uma curiosidade ingênua (desarmada e associada ao senso comum, e que será criticizada) para uma curiosidade epistemológica. Não se trata de uma ruptura, mas de uma superação de pontos falhos nas concepções pessoais daquele que aprende. A ideia é mostrar ao estudante que seus conhecimentos prévios podem não se aplicar a algumas situações da realidade, por falta de coerência (CAMPOS, NIGRO, 1999). Desse ponto em diante, o aluno deve ser despertado à aquisição de conhecimentos que ainda não detém, por meio de processos e interações ativas, indiciadas por problematizações que desafiem o aluno a pensar criticamente sobre situações reais que o cercam.

O momento pedagógico de ER parte desse princípio, ou seja, os alunos são desafiados à dialogicidade e estimulados a exporem suas ideias e opiniões. Nesse momento, as concepções dos estudantes sobre uma determinada problemática são colocadas em conflito, fomentando a necessidade de mais conhecimento sobre a situação debatida (DELIZOICOV; ANGOTTI, 1990; DELIZOICOV; ANGOTTI; PERNAMBUCO; 2002, 2009). 
Em nossa intervenção, durante o "Estudo da Realidade", foi possível perceber aspectos convergentes à valorização dos saberes prévios dos envolvidos, ao mesmo tempo em que se induziu provocações sobre conceitos internalizados pelos estudantes que destoam da realidade. A palestra ministrada pelo pesquisador na etapa de "Sensibilização" trouxe informações relativas à diversidade faunística da Mata Atlântica com enfoque nas espécies encontradas no estado do Espírito Santo, nos biomas característicos e nas áreas naturais da região. Após explanação inicial, foi aberta uma sessão de bate-papo em que se fez perceptível o embate de "ideias" prévias dos estudantes com os conhecimentos científicos compartilhados pelo preletor, pois alguns alunos concebiam o fato de que vários animais nativos só poderiam ser encontrados em savanas e florestas africanas. Esse embate, portanto, traduz dois possíveis cenários que, embora inconvenientes, requerem uma reflexão: a ciência parece muito distante da leitura de mundo que a maioria dos estudantes possui ou as informações científicas propagadas pela mídia e meios de comunicação não refletem, fidedignamente, uma realidade.

Uma outra percepção interessante desse momento pedagógico é o próprio desconhecimento da maioria dos estudantes sobre a existência de diversos "espaços naturais" com grande potencial faunístico, em seu próprio contexto geográfico. Embora a exploração de espaços não formais e informais de educação tenha o mérito de favorecer experiências que talvez não sejam possibilitadas pela escola, seu uso e "acesso" parece não ser uma prática para grande parte dos estudantes da Educação Básica (MARANDINO, et al., 2009).

Esta fase de ER encerrou-se com a apresentação do "Clube de Observadores" por meio do qual, posteriormente, os alunos foram estimulados a observarem/conhecerem mais sobre a natureza faunística (saberes esses ainda não construídos/internalizados por eles) e se integraram a uma proposta de trabalho investigativa e ao mesmo tempo artística e cultural: a fotografia.

\section{Organização do conhecimento (OC)}

O momento de OC é caracterizado pelo estudo dos conhecimentos científicos necessários à ampliação dos saberes prévios dos estudantes (DELIZOICOV; ANGOTTI; PERNAMBUCO; 2002). Nessa fase ocorre a mediação do professor/pesquisador na orientação das atividades que irão propiciar o levantamento de informações para uma construção ativa e consciente de novos conhecimentos, de modo a ampliar o repertório cultural e a autonomia dos envolvidos.

Em nosso estudo, a "OC" foi organizada por meio de atividades de observação da natureza dentro e fora do contexto escolar. Inicialmente, os alunos foram conduzidos ao pátio da escola onde puderam pôr em prática algumas técnicas de observação e de melhor "captação" dos animais em seus habitats naturais. Os alunos receberam da equipe coordenadora do projeto, 
instruções sobre conhecimentos básicos de observação dos animais e técnicas sobre como encontrar determinadas espécies e, posteriormente, identificá-las.

Além da própria equipe vinculada ao Instituto Últimos Refúgios, os alunos tiveram a mediação da professora de Ciências e de Observadores de Aves que trouxeram curiosidades acerca de alguns bichos típicos de ambientes urbanos. O presidente do Instituto participou da interação trazendo grandes contribuições de sua experiência enquanto "fotógrafo da natureza", cujas fotos foram apresentadas como inspiração para 0 trabalho de observação investigativa a ser realizado pelos alunos.

A escolha pela iniciação em ambiente escolar permitiu apurar nos estudantes a percepção de que natureza constitui parte de nosso cotidiano. Essa noção é um pressuposto da Educação Ambiental que nos desafia em torno de questões reais, pois nos permite reabitar coletivamente "[...] nossos meios de vida, de modo responsável [...] aprender a viver juntos - entre nós e humanos, e também com outras formas de vida que compartilham e compõem nosso meio ambiente" (SAUVÉ, 2005, p. 4).

A organização do conhecimento propiciou ainda o uso de TDICs, por meio da plataforma Biofaces e de smartphones (utilizados tanto para os registros fotográficos dos próprios alunos como para acesso à plataforma). Os alunos criaram um perfil no site, para posterior postagem de suas fotos autorais e compartilhamento das informações sobre os animais (Figura 2).

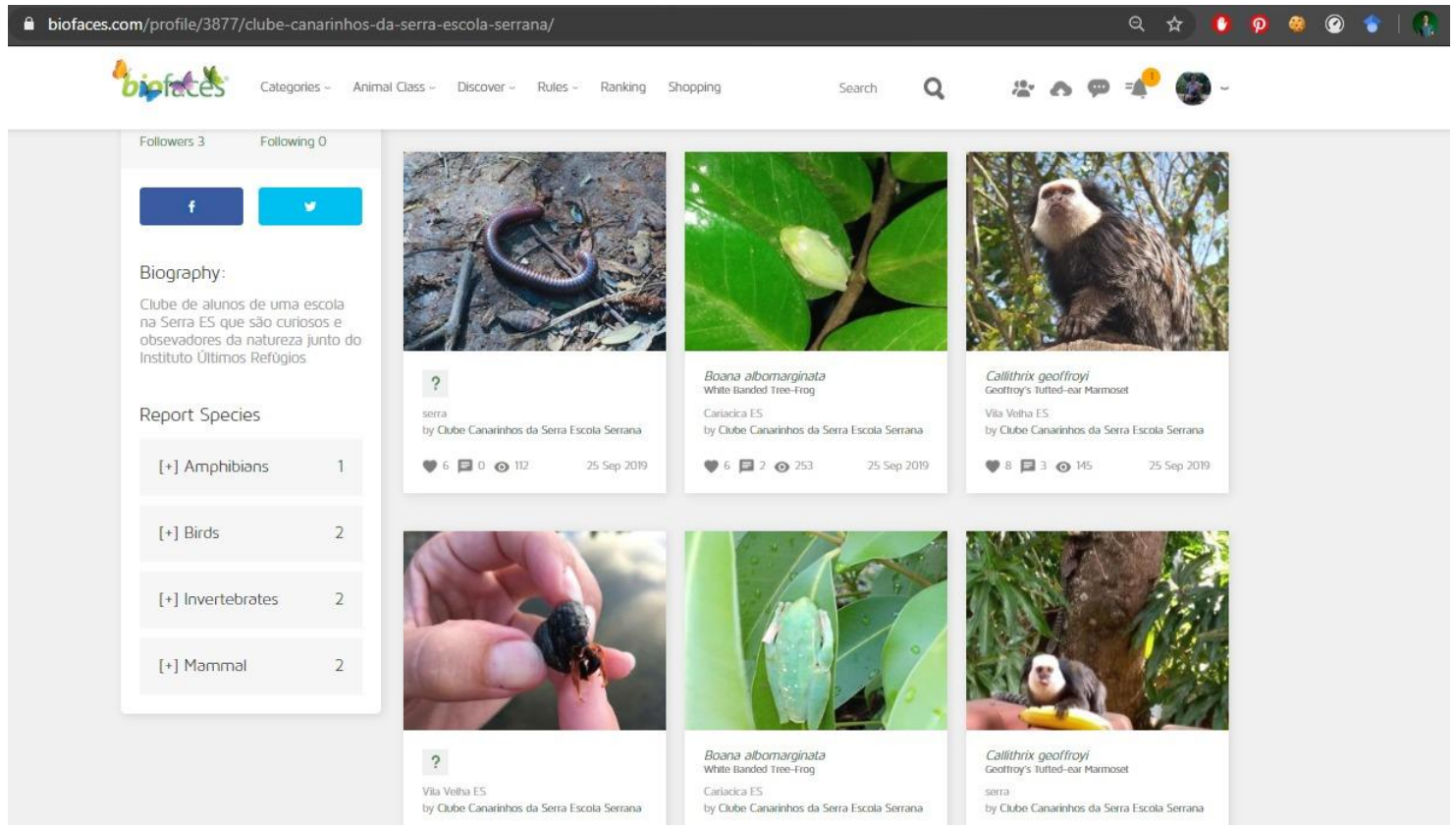

Figura 2: Perfil dos alunos criado para uso da plataforma Biofaces. 
escola. A consciência sobre a necessidade de busca por mais informações e conhecimentos (uma prerrogativa do momento de "Organização do Conhecimento" preconizado por Delizoicov) ganhou enlevo nesse momento em que os alunos passam a questionar: "Se aqui observamos tantos animais, como a quantidade de espécies deve ser muito maior em outros espaços naturais?"

Após essa primeira experiência de observação, os alunos participaram de visitas a quatro espaços não formais de educação: Horto da Serra, APA Mestre Álvaro, Ilha do Frade e Parque Botânico da Vale. Como já mencionamos, essas áreas foram escolhidas por terem elementos naturais diferentes entre si, por serem acessíveis para a realização das atividades e por estarem próximas à localidade escolar (Figura 3 ).
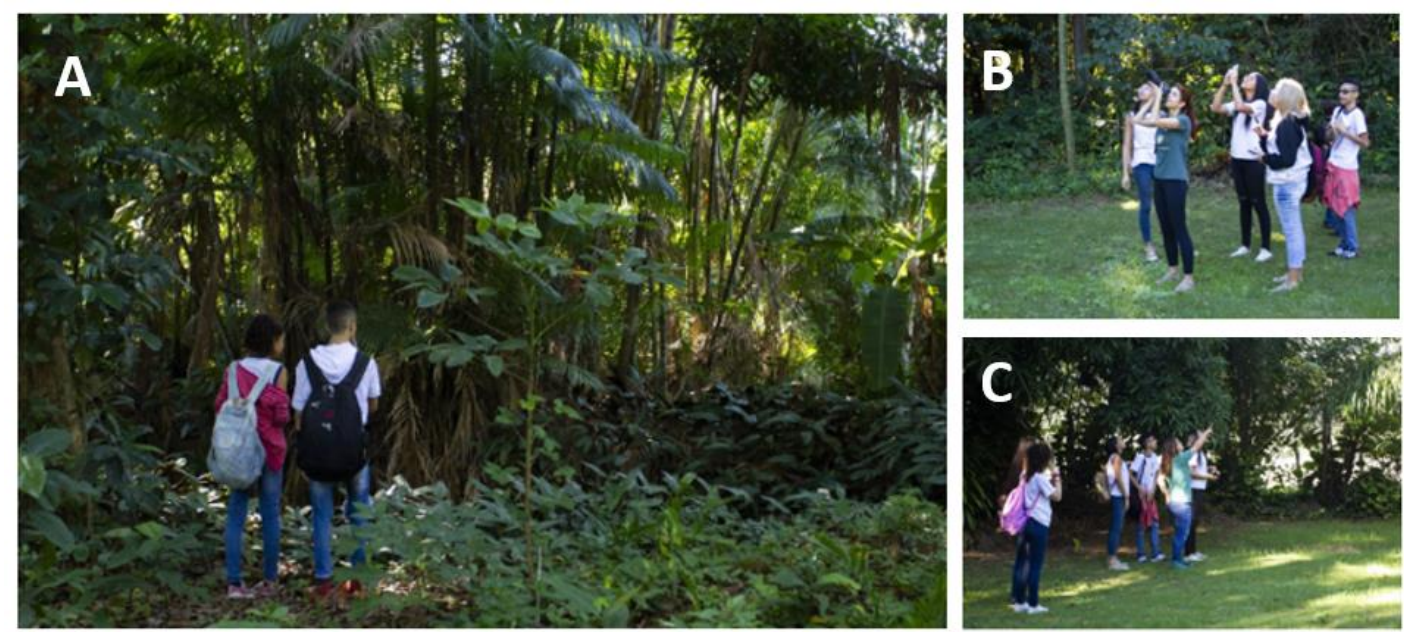

Figura 3: Primeira Saída a campo com os alunos ao Jardim Botânico Horto da Serra Município de Serra - ES. A: Alunos observando atentamente possíveis animais a serem avistados; B: Alunos fotografando aves planando pelo céu; C: Voluntária passando os conhecimentos aos alunos.

As visitas de campo foram consideradas o "clímax" do momento pedagógico de "OC", pois os alunos demonstraram uma ampliação do potencial de observação e análise da natureza, como perceptível em suas produções fotográficas.

Com isso, vislumbramos como os espaços não formais de educação tem potencial de favorecer experiências e vivências que talvez não sejam possibilitados pela escola, pela carência estrutural ou pela especificidade que esses locais apresentam em seus acervos únicos. Reforçamos a importância desses espaços surge em um contexto de desenvolvimento científico e tecnológico da humanidade, decorrente da necessidade de alfabetizar cientificamente os diversos estratos sociais (MARANDINO et al., 2009). Considerando que os alunos participantes da pesquisa eram provenientes de escolas públicas, a relevância desse estudo também se deu no alcance de sua 
intervenção: socialização de conhecimentos científicos para grupos e comunidades humanas historicamente desfavorecidas.

A primeira saída a campo realizada foi ao Horto da Serra (localizado no Município de Serra - ES). O local apresenta uma infraestrutura com praças e áreas para práticas esportivas, margeado por um grande lago e cercado por mata nativa. A formação geográfica do lugar permitiu aos alunos a visualização de aves aquáticas como o Biguá (Phalacrocorax brasilianus) e o FrangoD'água (Gallinula chloropus), além de espécies como Bem-te-vi (Pitangus sulphuratus), Pica-pau-anão-barrado (Picumnus cirratus), insetos e o carismático Sagui-da-cara-branca (Callithrix geoffroyi).

A segunda visita aconteceu na APA Mestre Álvaro (Figura 4) que é uma das áreas naturais de preservação do município de Serra, considerada uma das maiores elevações litorâneas do país em bioma de Mata Atlântica nativa (PEREIRA, 2019). O local possui uma ampla biodiversidade, atraindo cientistas de diversas áreas. Foi possível registrar espécies como a Gavião-carrapateiro (Milvago chimachima), Garça-branca-grande (Ardea alba) e até mesmo a Borboleta pororó-azul (Hamadryas Arete) que é uma variedade de inseto ainda não descrita em pesquisas na APA.
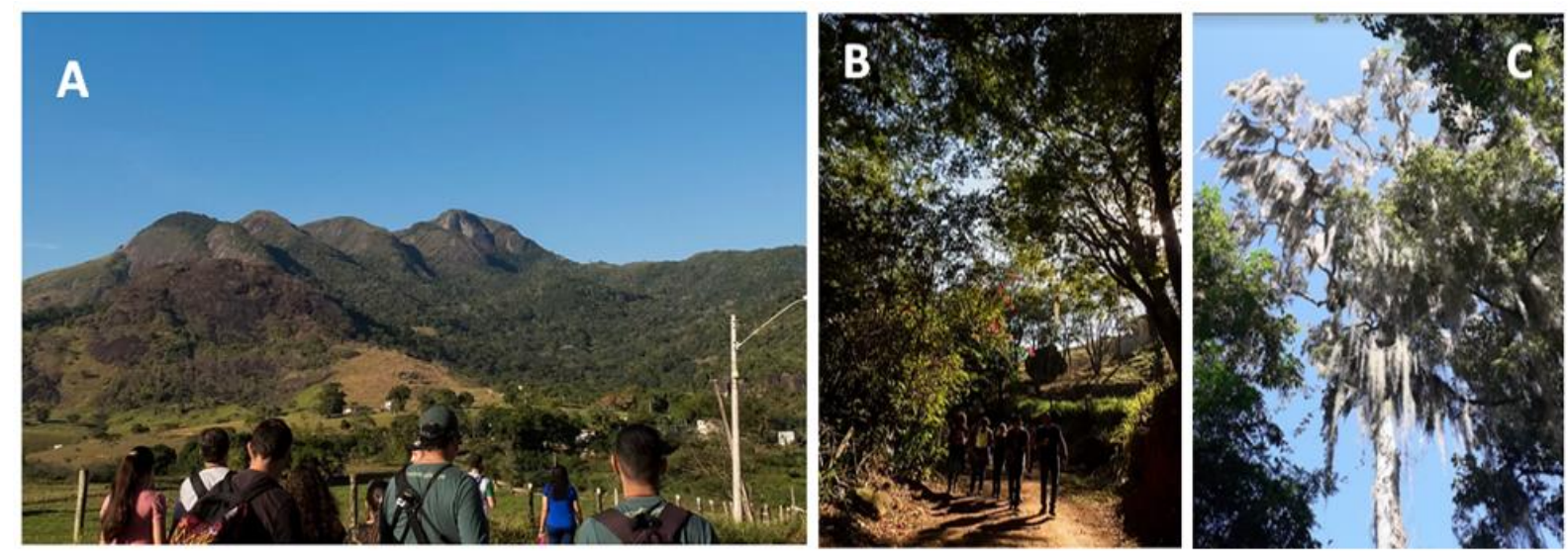

Figura 4: Visita à APA Mestre Alvaro, Serra-ES. A: Alunos caminhando para o acesso a APA Mestre Álvaro; B: Pais e alunos andando em uma das trilhas das APA; C: Árvore fotografada por um dos alunos na trilha.

A terceira visita foi realizada na llha do Frade (localizada em Vitória-ES), selecionada por estar dentro de uma área urbana (Figura 5). O local é seguro, de fácil acesso e abriga uma variedade de espécies marinhas, inclusive desconhecidas pelos alunos, tais como: Maçarico-branco (Calidris alba), Pirupiru (Haematopus palliatus) e Tartaruga-marinha (Calidris alba). 


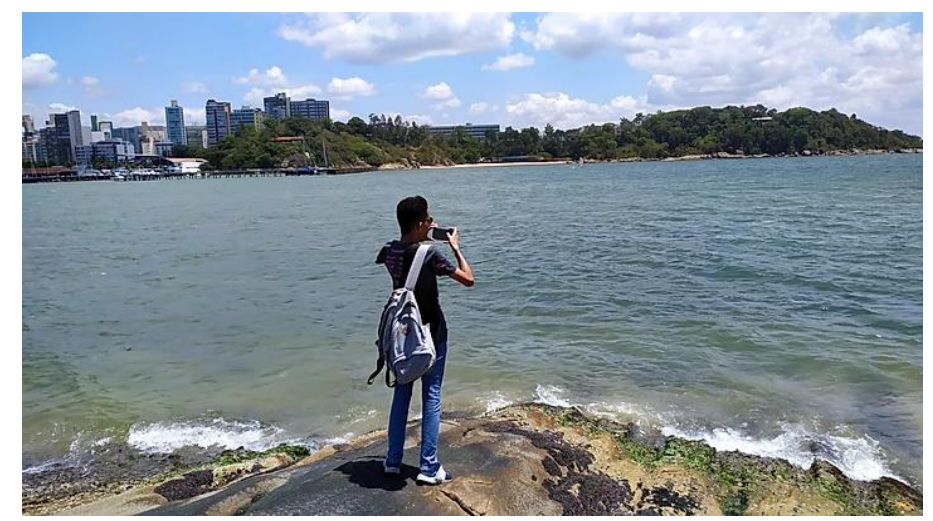

Figura 5: Aluno do 9ำ ano fotografando a paisagem da ilha.

A última visita a campo ocorreu no Parque Botânico da Vale (Figura 6), localizado na região urbana de Vitória-ES. Esse espaço possui uma área natural preservada com trilhas na mata que dão acesso a lagoas, o que facilita a visualização de animais silvestres como Jacaré-do-papo-amarelo (Caiman latirostris) e aves marinhas como o Biguá (Phalacrocorax brasilianus). As trilhas são preparadas para atividades que propiciem o estudo de Educação Ambiental e, por meio de placas informativas, dão destaque a árvores importantes, tais como a Boleira (Joannesia princeps) e o Pau-brasil (Paubrasilia echinata).

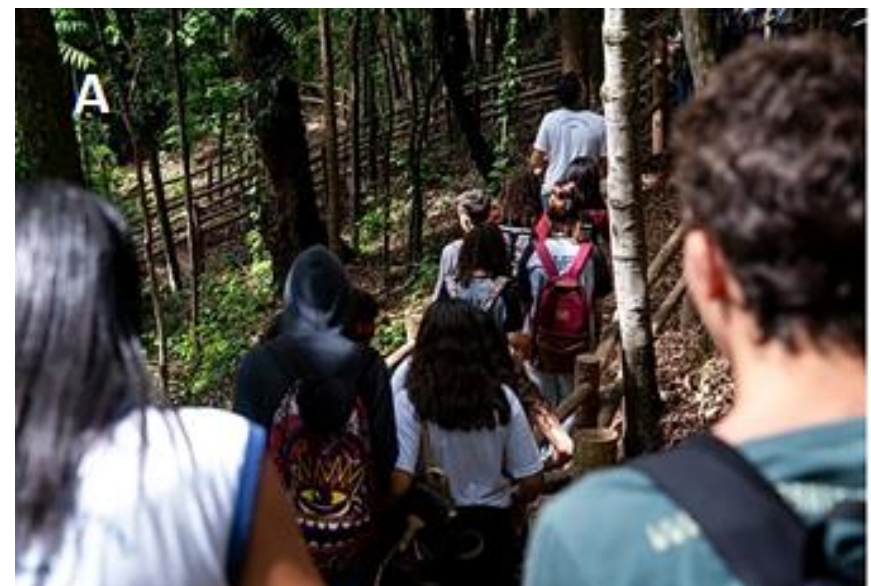

Figura 6: Alunos seguindo a trilha projetada dentro do Jardim Botânico da Vale

Como pleiteado pelo segundo momento pedagógico de "OC", durante as visitas, os alunos foram orientados a registrar os seres vivos da fauna e da flora que fossem percebidos por eles. Ao longo das anotações pessoais dos estudantes, os professores da escola e os pesquisadores presentes intervieram para colocações pertinentes e esclarecimento de dúvidas, ampliando as reflexões e enriquecendo o processo formativo. Assim, concordamos com Moreira (2018, p. 226) que 
Optar pela aprendizagem ativa e o ensino centrado no aluno é flertar com o conceito de prática deliberada que envolve o aprendiz na resolução de um conjunto de tarefas ou problemas que são desafiadores, mas factíveis, viáveis, e que envolvem explicitamente a prática de raciocínio e desempenho científicos. O professor, ou mediador, oferece incentivos apropriados para estimular os alunos a dominar as competências necessárias, assim como uma contínua realimentação para mantê-los ativos.

Durante as trilhas foi conversado com os alunos sobre questões ambientais e de ecologia. Como professores de outras disciplinas foram convidados a participarem das aulas de campo, os alunos puderam também ter uma visão interdisciplinar dos ambientes naturais e de suas riquezas. A interdisciplinaridade, em casos como o aqui narrado, permite uma interligação entre diferentes conhecimentos estabelecendo relações com o contexto da comunidade da qual o aluno faz parte e se constitui (BONATTO, 2012).

Ao final das trilhas, os alunos foram reunidos para que pudessem falar, de forma voluntária, sobre a experiência, sobre as espécies encontradas, registradas e fotografadas. Nesse momento, deu-se liberdade para que os estudantes pudessem expor o que observaram, bem como as espécies curiosas encontradas, antes desconhecidas.

Todas as anotações foram arquivadas para que fossem contabilizadas as espécies e para que fosse possível montar uma lista geral dos registros feitos pelos próprios estudantes. As fotografias foram, posteriormente, compartilhadas no site Biofaces pelos alunos, com uma legenda descritiva contendo a localização, o nome científico e a identificação do autor da foto, conforme apresentamos no momento seguinte de "aplicação do conhecimento".

Dentre as espécies observadas durante todo o projeto, foram contabilizadas pelos alunos cerca de 10 insetos, 3 répteis, 3 anfíbios, 1 mamífero e 37 aves. A experiência dos observadores de aves foi essencial para que as espécies desse grupo fossem identificadas, tendo sido a classe mais contabilizada, inclusive com registro de espécies inéditas para os alunos.

\section{Aplicação do conhecimento (AC)}

A aplicação do conhecimento é considerada uma etapa fundamental para a perspectiva cidadã da ciência. Trata-se de um momento em que os saberes científicos passam a fazer sentido para aqueles que experimentam de seus atos. Durante a "AC", os conhecimentos incorporados pelos estudantes são abordados sistematicamente para análise e interpretação de situações pioneiras que foram indiciadas, bem como outras questões não diretamente vinculadas ao "estudo da realidade" feito inicialmente (DELIZOICOV; ANGOTTI, 1990, p.; DELIZOICOV; ANGOTTI; PERNAMBUCO; 2002, p.; 2009). 
No presente estudo, durante as conversas em momentos de campo, foi destacada a facilidade de "perceber" diferentes formas de vida em qualquer ambiente, seja ele urbano ou rural, com o intuito de aproximar as atividades propostas da realidade dos alunos. A aplicação dos conhecimentos fomentados nos espaços visitados se deu também nessa perspectiva, quando recebemos dos alunos fotos de insetos e pássaros que os mesmos registraram em suas casas e nos lugares que convivem.

A "AC" foi concluída em espaço escolar com a inserção das fotos e informações das espécies registradas (Figura 7) na plataforma Biofaces. Durante esse momento, foi possível estabelecer interações discursivas entre os estudantes e a professora de Ciências para "identificação" das espécies fotografadas, acréscimo de "nome científico" e devida caracterização da classe dos "animais" reportados em mural digital.
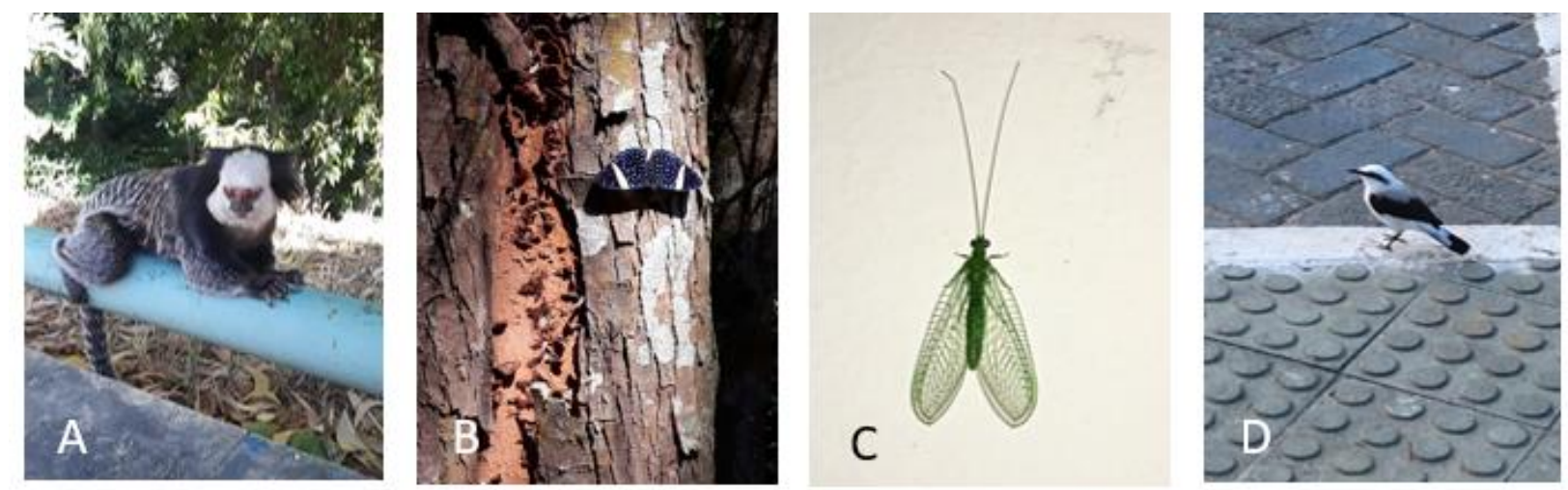

Figura 7: Fotos feitas pelos alunos. A: Sagui fotografado por um aluno do $7^{\circ}$ ano; B: Borboleta fotografada por uma aluna do $7^{\circ}$ ano; C: Inseto fotografado por uma aluna do $9^{\circ}$ Ano; D:

Passarinho fotografado uma aluna do $9^{\circ}$ Ano.

Nesse processo, alunos provenientes de regiões rurais demonstraram seus conhecimentos sobre espécies de aves que já conheciam de seus próprios contextos locais, o que auxiliou aos demais colegas na identificação de exemplares de aves fotografadas nos locais de visitação.

Como preconizado por Delizoicov (2009) a meta pretendida com o momento "AC" é justamente o emprego constante e rotineiro dos conhecimentos científicos em situações reais, capacitando os estudantes ao "uso" consciente da ciência para atuarem na sociedade e com propostas resolutivas para os problemas que os afligem.

Encerrando a discussão deste tópico, investiu-se na divulgação do trabalho realizado pelos alunos por meio de notícias publicadas no site do Instituto Últimos Refúgios. A investigação - um processo inerente ao método científico - seguiu, portanto, uma lógica de: produção do conhecimento, validação e sua comunicação às sociedades. Da mesma forma, no presente estudo, os registros feitos pelos alunos foram socializados ao público geral por meio de textos de divulgação institucional (notícias) como um processo que valida o caráter social da ciência: sua popularização. 


\section{Considerações finais}

"A natureza é uma coisa tão bela de se ver, de se sentir, é uma coisa que se parássemos para pensar é rara ${ }^{4}$.

Ana Clara

A proposta do "Clube de Observadores da Natureza" idealiza um mundo onde as pessoas possam reconhecer a importância dos ambientes naturais e se aproximar deles de forma sustentável.

O contato com o ambiente natural em situações de aprendizagem de Ciências; pode se apresentar como alternativa promissora na abordagem didática de conceitos biológicos bem como amplia o repertório de saberes que passam a fazer sentido para o sujeito em formação.

A intervenção pedagógica por meio de aulas de campo (Figura 8) favorece uma ressignificação desses espaços em que a natureza tem seu papel ampliado para além de um recurso utilitário, alcançando um viés de instrumentação e conscientização ambiental. A criança que convive com o meio natural e desenvolve afinidade em relação à ele aprende a apreciá-lo e passa a zelar pelo mundo à sua volta, pois o respeita e o reconhece como seu ambiente de pertencimento. Torna-se, assim, um agente de mudanças em sua própria comunidade.
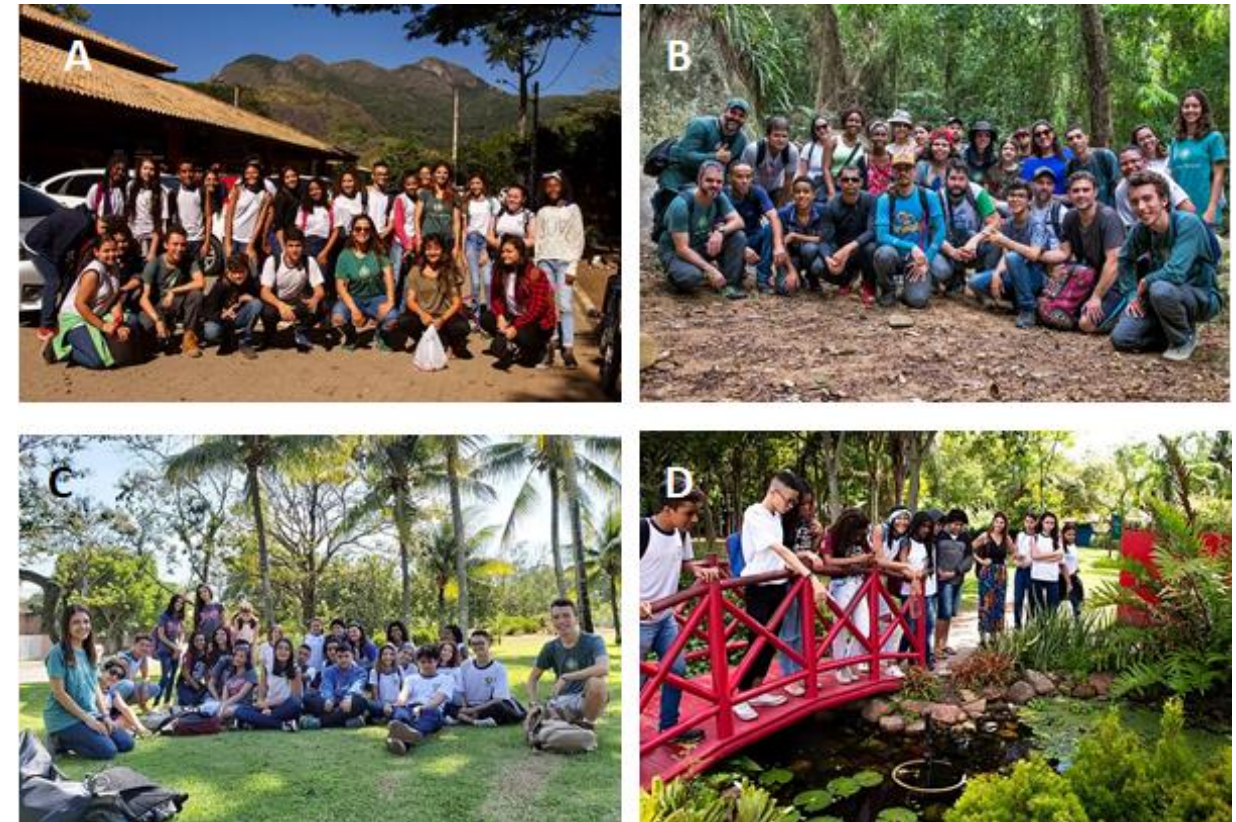

Figura 8: Alunos e responsáveis reunidos ao final de saídas à campo. A: Horto da Serra, Serra- ES; B: APA Mestre Alvaro, Serra - ES; C: Ilha do Frade, Vitória - ES; D: Parque Botânico Vale, Vitória - ES

${ }^{4}$ Trecho de poema elaborado por aluna do $7^{\circ}$ ano participante da pesquisa de intervenção. 
Por intermédio da pesquisa de intervenção apresentada, foi possível conciliar o estudo de Educação Ambiental com as prerrogativas da cidadania da ciência. A aplicação dos três modelos pedagógicos de Delizoicov (2009) serviu como alicerce para esse alinhamento em que se busca um ensino de ciências mais contextualizado, crítico e consciente. Isso implica um conhecimento acerca dos fazeres e das responsabilidades cotidianas da ciência, da linguagem científica e da decodificação das crenças aderidas a ela (AGUILAR, 1999). Envolve o processo de popularização dos saberes próprios da ciência, de modo a favorecer a democratização do ensino, pela difusão de uma aculturação científica, devidamente autônoma, totalizante e cidadã.

"Porque será que nós seres humanos muitas vezes não agimos com a cabeça? Será que nós não percebemos o quanto fomos mal a natureza?" Questões pertinentes levantadas por uma aluna participante deste estudo e que nos levam a uma reflexão oportuna: viver juntos em nosso planeta é certamente o desafio ético e político mais exigente e mais fundamental de nossas sociedades urbanizadas! (SAUVÉ, 2005).

\section{Referências}

AGUILAR, T., Alfabetización científica para la ciudadanía. Madrid: Narcea, 1999.

BONATTO, A.; BARROS C. R.; GEMELI, R. A.; LOPES, T. B \& FRISON, M. D. Interdisciplinaridade no ambiente escolar. IX ANPED SUL, Rio Grande do Sul, v. 9, p. 1-12, 2012.

BRASIL. Ministério da Educação. Base Nacional Comum Curricular. Brasília, 2016.

CAMPOS, M.C.C; NIGRO, R.G. Didática de ciências: o ensino-aprendizagem como investigação. São Paulo: FTD, v. 199, 1999.

CARVALHO, A.M.P. Ensino de ciências por investigação: condições para implementação em sala de aula. Cengage Learning, São Paulo, p.1-20, 2013.

CAPECCHI, M.C.V.M. Problematização no ensino de ciências. In: CARVALHO, A.M.P. (org.). Ensino de Ciências por Investigação: Condições para Implementação em sala de aula. São Paulo: Pioneira Thomson Learning, p. 21 39, 2014.

CHARLES, C.; LOUV, R.; BODNER, L.; GUNS, B. Children and nature 2008: A report on the movement to reconnect children to the natural world. Santa $\mathrm{Fe}$, NM: Children \& Nature Network, p. 9-12, janeiro, 2008. Disponível em: <> http://www.cnaturenet.org/uploads/CNMovement.pdf Acesso: 10 Set. 2020.

DAMIANI, M. F., ROCHEFOT, R. S., CASTRO, R. F. de, DARIZ, M. R., PINHEIRO, S. S. Discutindo pesquisas do tipo intervenção pedagógica. Cadernos de Educação, Rio Grande do Sul, n. 45, p. 57-67, mai/ago. 2013. 
DELIZOICOV, D.; ANGOTTI, J. A. Metodologia do ensino de ciências, Titulo do Periódico. São Paulo: Cortez, 1990.

DELIZOICOV, D.; ANGOTTI, J. A.; PERNAMBUCO, M.M. Ensino de ciências: fundamentos e métodos. São Paulo: Cortez, 2002.

DELIZOICOV, D.; ANGOTTI; J. A.; PERNAMBUCO, M. M. C. A. Ensino de Ciências: fundamentos e métodos. 3 ed. São Paulo: Cortez, 2009.

FREIRE, P. À Sombra desta Mangueira, São Paulo, Olho d'Água, $5^{a}$ edição, 2003.

LAYRARGUES, P.P. Muito além da natureza: Educação Ambiental e reprodução social. Pensamento complexo, dialética e Educação Ambiental. São Paulo: Cortez, p. 72-103, 2006.

LIMA C. A. COPELLO, M. I. Educação Ambiental desde o enfoque ciência/tecnologia/sociedade (CTS) - um possível caminho. Pesquisa em Educação Ambiental, v.2, n.2, pp.173-196, Jul. 2007.

LOUV, R. et al. Children and nature-deficit disorder. Countryside Recreation, v. 17, n. 2, p. 3-5, 2009.

LOUREIRO, C.; LIMA, J. Educação Ambiental e educação científica na perspectiva Ciência, Tecnologia e Sociedade (CTS): pilares para uma educação crítica. Acta Scientiae, Canoas, v.11, n.1, p.88-100, jan/jun, 2009.

MAMEDE, S; BENITES, M; ALHO, C J R. Ciência cidadã e sua contribuição na proteção e conservação da biodiversidade na reserva da biosfera do Pantanal. Revista Brasileira de Educação Ambiental, São Paulo, v. 12, n. 4, p. 153164, 2017.

MARANDINO, M; SELLES, S. E.; FERREIRA, M. S. Ensino de Biologia: histórias e práticas em diferentes espaços educativos. Cortez Editora, 2009.

MARINHO, A. Atividades na natureza, lazer e Educação Ambiental: refletindo sobre algumas possibilidades. Motrivivência, n. 22, p. 47-70, 2004.

MOREIRA, M. A. O ensino de STEM (Ciência, Tecnologia, Engenharia e Matemática) no século XXI. Revista Brasileira de Ensino de Ciências e Tecnologia, v.11, n.2, p. 14-23, 2018.

NAÇÕES UNIDAS BRASIL: Objetivos dos Desenvolvimento Sustentável no Brasil, 2021, Disponivel em: <https://brasil.un.org/pt-br/sdgs>, Acesso em: 24 de Jun de 2021

PADOAN, L.L.F. Explorando o desconhecido: As contribuições dos viajantes naturalistas para as Ciências Naturais no Brasil do século XVIII e XIX. Revista do Centro do Ciências Naturais e Exatas, v. 19, n. 1, p. 194-201, 2015.

SASSERON, L.H. Interações discursivas e investigação em sala de aula: o papel do professor. In: Ensino de Ciências por investigação: condições para implementação em sala de aula. São Paulo: Cengage Learning, p. 40 - 61, 2013. 
SAUVÉ, L. Educação Ambiental: possibilidades e limitações. In: Educação e Pesquisa. São Paulo, v.31, n.2, p.317-322, maio/ago, 2005.

SOUSA, F.O. et al. Etnoherpetologia com ênfase em Tupinambis Merianae (DUMÉRIL \& BIBRON, 1839) (SQUAMATA: TEIIDAE) em comunidades rurais do semiárido cearense, Paraiba, Out. 2016. Disponível em: http://dspace.sti.ufcg.edu.br:8080/jspui/handle/riufcg/7499 Acesso em: 10 Set. 2020.

SANTOS, C. R. S.; CHASSOT, A. I.; CORTE, V. B. Educação científica e popularização da ciência: o ensino por investigação como abordagem didática. Revista Brasileira de Ensino de Ciências e Matemática, v. 3, n. 2, p: 1-18, 2020.

TEIXEIRA, P. M. M. A educação científica sob a perspectiva da pedagogia histórico---crítica e do movimento c.t.s. no ensino de ciências. Ciência \& Educação, v.9, n.2, p.177---190, 2003..

VANZOLINI, P. E. A Contribuição Zoológica dos Primeiros Naturalistas Viajantes. Revista USP, n. 30, p. 190-238, 1996. Disponível em: https://www.revistas.usp.br/revusp/article/download/25918/27650 Acesso em: 10 Set. 2020. 